\title{
O Projeto Educacional de Rui Barbosa: A questão do Ensino de Geografia e o Método Intuitivo
}

\begin{abstract}
Resumo: 0 presente trabalho tem como objetivo apresentar uma breve discussão a respeito do projeto educacional de Rui Barbosa (1849-1923), expressa nos pareceres acerca da Reforma do Ensino Primário de 1883, e da Reforma do Ensino Secundário e Superior de 1882. Assim como, analisar a questão do ensino de geografia por ele defendido, o qual perpassava pela imperiosa reformulação do método de ensino. Rui Barbosa fez um minucioso levantamento sobre a situação do ensino no Brasil, tomando como suporte teórico os decretos e documentos existentes fora e dentro do país, que versavam sobre a educação. Trata-se, portanto de um importante documento para a entendermos a história da educação brasileira, bem como a constituição da nação e do povo brasileiro, sobretudo, pela amplitude e profundidade como discutiu cada aspecto da educação escolar, e nele o ensino de geografia.
\end{abstract}

\section{The Education Project of Rui Barbosa: The issue of Teaching Geography and Intuitive Method}

\footnotetext{
Abstract: This paper aims to present a brief discussion about the educational project of Rui Brabosa (1849-1923), the opinions expressed on the Reform of Primary Education,1883, and the Reforn of Secondary and Higher Education, 1882. As such, consider the question of teaching geography advocated by him, which pervaded the urgent reforn of the teaching method. Barbosa made a detailed survey on the situation of education in Brazil, taking as theorical support existing decress and documents inside and autside the country that focused on education. It is therefore an important document to understand the history of Brazilian education, as well as the constitution of the nation and the Brazilian people, especially the breath and depth as discussed every aspect of school education, and teaching him geografphy.
}

Najla Mehanna Mormul* Maria Cristina Gomes Machado ** Eduardo Donizeti Girotto***

*Professora do curso de Geografia da Universidade Estadual do Oeste do Paraná- Campus de Francisco Beltrão. Doutoranda em Geografia na UEM.

** Professora co curso de Pedagogia da Universidade Estadual de Maringá. Doutora em Educaçãa.

*** Professor do curso de Geografia da Universidade Estadual do Oeste do Paraná - Campus de Francisco Beltrão. Doutorando em Geografia na USP.

Palavras-chave: Rui Barbosa; Ensino de Geografia; Método Intuitivo.

Key-words: Rui Barbosa; Teaching Geography; Intuitive Method. 
${ }_{1}$ Pareceres acerca da "Reforma do Ensino Primário e as Várias Instituições complementares", de 1883, e da "Reforma do Ensino Secundário e Superior", 1882. Nos pareceres de Rui Barbosa sobre ensino, há uma fonte valiosíssima de informações, uma vez que ele não poupou esforços ao fazer um levantamento minucioso da situação do ensino no Brasil. Os pareceres são, indubitavelmente, uma importante fonte de investigação histórica.

Geografia Ensino \& Pesquisa, v. 15, n.3, p. 154 166, set./dez. 2011

O Projeto Educacional de Rui Barbosa: A questão do Ensino de Geografia e o Método Intuitivo

\section{O Papel da Educação e do Ensino de Geografia na Construção da Identidade Nacional no século XIX.}

A educação no Brasil no século XIX era vista como algo de extrema importância, dada as condições sociais, econômicas e políticas do momento. A corrida em busca da modernização da nação e a construção de uma unidade e identidade nacional eram consideradas necessárias e poderiam ser alcançadas via educação. No entanto, para isso, foram necessárias a adoção de algumas medidas políticas, econômicas e administrativas, que contribuiram para conduzir o país rumo ao progresso.

Rui Barbosa (1849 - 1923) não relutou em valorizar a educação em seus pareceres ${ }^{1}$, mostrando como a educação escolar poderia ser um importante meio para alcançar o progresso, assim como para a formação do cidadão. Soube, com muita precisão, ponderar o que competia a cada uma das disciplinas escolhidas para compor o currículo escolar brasileiro. Dessa forma, os conteúdos deveriam estar de acordo com as expectativas e necessidades do momento.

\begin{abstract}
A escola foi colocada, assim, como condição de progresso. Este não significava apenas progredir materialmente. Significava, também, a possibilidade de manutenção da ordem necessária da sociedade burguesa. Para resolver os problemas postos com o avanço das idéias socialistas, que pregavam a subversão das relações de produção burguesas, ganhavam força os ideais democráticos. Apenas estes ideais poderiam absorver os interesses conflitivos resultantes da luta de classes MACHADO, 2004, p. 77).
\end{abstract}

Diante deste cenário, indaga-se "Como a geografia poderia contribuir para a consolidação política da nação brasileira, bem como para a construção de uma identidade e unidade nacional?". Verifica-se que Rui Barbosa não elegeu a geografia como a disciplina mais importante do rol por ele elencado, mas isto não significava que ela não era importante ou necessária; com esse intuito, buscar-se-ão possíveis respostas para esta questão.

É patente que o ensino de geografia passou a ter mais fôlego a partir do clamor em prol da educação pública e da busca por uma educação que rompesse com o formalismo, ou seja uma educação voltada para as massas e capaz de formar o cidadão por ora almejado.

Para elucidar esse assunto, acredita-se ser importante verificar brevemente como a visão da construção da identidade nacional e da consolidação da nação era percebida em nosso país, já que o Brasil, como antiga colônia de Portugal, tinha muito de sua história associada com a daquele país. A influência portuguesa em solo brasileiro deixou profundas marcas na constituição da nossa nação. Como uma colônia de exploração, ficou, durante muitos anos, atrelada às vontades e necessidades de nossos colonizadores portugueses. Quanto à formação da população brasileira, são evidentes os vestígios de nossa miscigenação. Assim, não podemos passar uma borracha e reescrever uma nova história brasileira sem considerar a participação de Portugal nesse cenário.

A condição de colônia portuguesa garantiu ao Brasil, durante muitos séculos, o rótulo de nação atrasada. Portanto, para reverter esse quadro, seria urgente que 0 povo brasileiro conhecesse e amasse a pátria, mas a concretude destes atos revelou-se a partir da independência, quando este sentimento tornou-se mais eminente. 
Para tanto, seria importante que o povo reconhecesse seu papel como cidadão brasileiro e 0 desempenhasse adequadamente. Diante disso, os conhecimentos geográficos poderiam contribuir.

A cidade do Rio de Janeiro, na década de 1880, parecia exalar geografia, abrigando desde 1838, o Instituto Histórico Geográfico Brasileiro (IHGB). Anos depois, foi criada, em 1883, a Sociedade de Geografia do Rio de Janeiro (SCRJ), além de outros ambientes similares. Entretanto isso não foi suficiente para a efetivação da identidade nacional, já que, no Brasil do século XIX, o sentimento de brasilidade não havia tomado forma nem consistência.

Quando foi criado o Instituto Histórico Geográfico Brasileiro (IHGB), este estava atrelado à necessidade inerente a todo e qualquer Estado nascente, ou seja, de apresentar um perfil para a nação brasileira, capaz de garantir uma identidade própria. Dessa casa, suscitaram várias propostas para a consolidação política da nação, o Instituto Histórico Geográfico Brasileiro, no decorrer de seu longo percurso, tornou-se um importante interlocutor dos grupos envolvidos com os projetos para a modernização do país.

Assim, o Instituto Histórico Geográfico Brasileiro, em 1847, buscando desenvolver um projeto para a história que ambicionava instituir-se, lançou mão de um concurso, cujo tema era: "Como se deve escrever a história do Brasil"2. O texto vencedor foi o de Karl Friederich von Martius (17941868), que escreveu um texto reconhecendo a diversidade regional e cultural no Brasil.

A idéia de nação desenvolvida no Brasil tinha o português como elemento principal e não 0 indígena - nativo brasileiro ${ }^{3}$. Entretanto, face à história patriótica e à geografia nacional, acabou por ascender nessa instituição, dada sua importância. Os criadores do IHGB tiveram como direção a idéia de ininterrupção, já que, para eles, a monarquia se apresentava como herdeira do domínio lusitano.

Em relação à Seção de Geografia, essa também foi criada nos moldes de uma política de continuidade, como a do IHGB, pensando o Brasil como prolongamento português, porém mais exarcebada, porque era mais evidente a presença da concepção lusitana, bem como sua influência nesse instituto. Porém, durante algumas administrações da Seção, a proposta lusitana foi enfraquecida, já que, em alguns momentos, a revista veiculou artigos muito próximos do romantismo, buscando explicar a inserção da cultura indígena na civilização nacional, pensada como costura entre o elemento português e o nativo.

Todavia a construção de uma identidade nacional compreendia que identificar o brasileiro era uma tarefa difícil, consistindo em entender os fatos que marcaram a história do país, como: a escravidão e a questão da cidadania, que se situavam entre os principais desafios para 0 pensamento brasileiro durante o século XIX. Desde a Independência, a elite compartilhava em desenvolver, ao mesmo passo, um projeto civilizador. Buscava-se a construção de uma nação desenvolvida, que precisava incorporar a população miscigenada em uma singular comunidade nacional.

Contudo, a introdução do povo na jovem nação estava no cerne dos debates. No entanto, alguns importantes intelectuais entendiam e recomendavam a construção de uma nacionalidade formada praticamente por brancos. Em 1857, foi publicada a obra "História Geral do Brasil" de Francisco Varnhagen ${ }^{4}$ (1856, p. 36-62), "[...] há animais que só podem viver e produzir no meio das trevas e se os levam para a presença da luz ou morrem ou desaparecem. Da mesma sorte, entre as diversas raças humanas, o índio parece ter uma organização incompatível com a civilização". Dessa maneira, ele considerava que a nacionalidade brasileira estava estritamente vinculada à concepção de civilização praticada na Europa.
2 Karl Friedrich Philippe von Martius venceu o concurso e discutiu parcialmente as teorias sobre a decadência dos nativos americanos, von Martius considerava os índios como populações que em breve deixariam de existir. 0 atual indígena brasileiro, segundo ele, não é senão o resíduo de uma muito antiga raça, posto que está perdida a história. 0 pessimismo foi mais contundente num texto anterior, de 1838, sobre "O Estado de Direito entre os Autóctones dos Brasil. Escreveu von Martius, não há dúvida: 0 americano está prestes a desaparecer. Outros povos viverão quando aqueles infelizes do Novo Mundo já dormirem 0 sono eterno (MONTEIRO, 2001, p. 3).

3 Sobre esse assunto, Lesser (2001, p. 293-294) comenta: "A identidade nacional brasileira inclui os de ascendência não-européia? A resposta é um sim condicionado. Alguns grupos de imigrantes foram capazes de ampliar 0 estreito paradigma nacional de um Brasil "branco" ou "europeu", enquanto outros insistem, com algum êxito, em que a "brancura" não é um componente necessário da cidadania brasileira. Isso tudo aconteceu num contexto de preconceito e discriminação, muitas vezes escancarados. Como, então, interpretar os dados? Eles decerto sugerem que o discurso aparentemente estático da elite foi rompido. A ampliação da identidade nacional para incluir outros grupos raciais permitiu que a elite brasileira fosse enriquecida, ao modesto custo de deixar enfurecidos alguns ideólogos abertamente racistas".

4 "Francisco Adolfo de Varnhagen, escreveu a primeira "História Geral do Brasil" a partir de uma ampla e pioneira investigação em documentos do período colonial. Ao refletir sobre os índios, ditou Varnhagen: "de tais povos na

Geografia Ensino \& Pesquisa, v. 15, n.3, p. 154 166, set./dez. 2011

Mormul, N. M.; Machado, M. C. G. Girotto, E. D. 
infância não há história: há só etnografia". Esta afirmação ecoava, sem dúvida, algumas visões já francamente em voga no Ocidente do século XIX, que desqualificavam os povos primitivos enquanto participantes de uma história movida cada vez mais pelo avanço da civilização européia e os reduzia a meros objetos da ciência que, quando muito, podiam lançar alguma luz sobre as origens da história da humanidade, como fosséis vivos de uma época muito remota. Varnhagen também tomava como ponto de partida uma postura claramente pessimista" (MONTEIRO, 2001, p.2-3).

5 "Raízes do Brasil, efetivamente, é um dos trabalhos que mais contribuem para a compreensão da evolução política da sociedade brasileira. Escrito na década de trinta, a agudeza de sua análise $e$ a pertinência dos problemas levantados ganharam força e atualidade com 0 passar dos acontecimentos. Muitas das discussões contemporâneas sobre os desenlaces possíveis do impasse político presente na sociedade brasileira muito teriam a ganhar com sua reflexão aberta e despretensiosa. A obra se move no contexto de uma problemática teórica tipicamente weberiana - a adequação de autoridade política do tipo legal racional a uma realidade onde predomina uma autoridade de molde tradicional ou carismática. A influência de Weber, entretanto, vai mais além. Penetra na própria obra onde a história comparada através de tipos ideais é o método de exposição utilizado. 0 esforço do autor é no sentido de mostrar que, como conseqüência do desenvolvimento de uma sólida base urbana e deslocamento do centro de gravidade do campo para a cidade, a questão da estruturação e adequação das instituições políticas estava colocada para a sociedade brasileira. E mais, o sentido de seu desenvolvimento (da sociedade

Geografia Ensino \& Pesquisa, v. 15, n.3, p. 154 166, set./dez. 2011

O Projeto Educacional de Rui Barbosa: A questão do Ensino de Geografia e o Método Intuitivo
Esse entendimento estava presente, também, no pensamento de José Bonifácio, que apoiou a formação da idéia de mestiçagem. Como deputado da Assembléia Constituinte de 1823, José Bonifácio viveu experiência análoga ao defender a miscelânea de brancos, negros e índios, porque via nisso um caminho que possibilitava amenizar as intensas disparidades raciais, promovendo o aprimoramento do pardo por meio da inserção do elemento cultural europeu. Acreditava que a mistura entre negros e índios resultaria numa miscigenação bem-sucedida. Mesmo imbuído de bons argumentos, o "patriarca da Independência" não conseguiu fazer com que sua tese ecoasse, já que o benefício da miscigenação, defendido por ele, encontrou algumas opiniões díspares. Embora preceituasse que 0 aspecto fundamental da identidade brasileira estava respaldado na cor branca, fruto da pujante presença européia em solo brasileiro.

Percebe-se que havia convergência entre os que defendiam a civilização exercida pelo elemento branco e aquela atrelada à mestiçagem, já que ambas associavam a formação da identidade brasileira ao embranquecimento dos indígenas e dos negros. Desse modo, o debate sobre a nossa nacionalidade repercutia sobre a cidadania do brasileiro, porque o embate racial percorria um caminho, no qual a participação do elemento negro e índio eram de grande importância, apesar de ser, na maioria das vezes, pormenorizada, não dava para ser esquecida.

Percorrendo um caminho inverso, José de Alencar (1829-1877), o então membro do Partido Conservador, intervinha defendendo a escravidão e aconselhando algumas restrições importantes aos direitos políticos. Em sua opinião, o assunto era deliberar quem, dentre aqueles que formavam o povo, teria acesso a direitos políticos.

Acreditava-se que seria necessário definir alguns critérios para garantir um eleitorado que assegurasse uma representação de qualidade. A defesa de José de Alencar ia ao encontro das teorias defendidas na Europa. Os requisitos para a escolha do eleitorado eram baseados na independência material, materializada pela propriedade ou pela renda, e pela aptidão intelectiva, alcançada por meio da educação.

Sérgio Buarque de Holanda (1902- 1982), num período posterior, escreveu seu livro "Raízes do Brasil"5 publicado pela primeira vez em 1936. O historiador, investindo em outra questão, ponderou as verdadeiras probabilidades de desenvolvimento da nossa sociedade. Para ele, atingir o que se almejava, estava sujeito ao enfrentamento dos conflitos deixados pelos princípios antiquados das antigas administrações, cujas elites colaboraram para a dependência econômica e a injustiça social da nação.

Entre os desafios do país por ele discutido, estava à superação do abismo existente entre a elite, a sociedade e o Estado, ou seja, considerava absurdamente alarmante a distância entre os interesses públicos e privados, sem deixar de citar a desagregação existente entre o mundo agrário e a crescente urbanização. Logo, para solucionar os problemas que afetavam o país, tornava-se necessário conhecer as raízes de nossos males.

Em sua obra, tornou-se possível verificar que o autor balizava o fim do domínio lusobrasileiro e vislumbrava o aparecimento de uma nova cultura, pautada na mistura entre os povos que compunham o território nacional. Salienta-se que um dos aspectos inovadores de "Raízes do Brasil" (BUARQUE DE HOLANDA 1999) era o conceito de "homem cordial". Esta cordialidade era caracterizada pela dificuldade do brasileiro em tratar com assuntos sociais ou políticos de forma racional e em encarar a esfera pública como algo impessoal ou como palco de conflitos entre interesses coletivos.

Por conta de interpretações equivocadas, esse conceito acabou por contribuir em fixar, no imaginário nacional, a idéia do brasileiro como um indivíduo passivo, ou seja, que aceitaria os abusos e devaneios da administração pública sem pestanejar. 
Nota-se, assim, que não foram poucos os intelectuais brasileiros ${ }^{6}$ que se enveredaram em discutir a questão da identidade nacional, bem como não foram poucos os percalços, encontrados ao longo da construção de nossa identidade. Esses caros representantes do pensamento brasileiro do século XIX foram responsáveis por deixar valiosas informações sobre essa questão.

Não obstante, seria ingênuo acreditar que saciaríamos o amplo e complexo universo que permeia esse assunto. Tão somente, não foram e não serão poucas as dúvidas que margearão conclusões futuras. Salienta-se que, para construir identidade, deve-se estar alicerçado sobre uma área definida como espaço geográfico, que se caracteriza pela ação humana sobre o meio, espaço este no qual estão expressos o modo como as pessoas se relacionam entre si e com o ambiente que ocupam.

Não é novidade que o Brasil, à medida que foi anexando territórios ao longo da história foi concomitantemente, buscando criar sua identidade. Identidade essa possível de ser construída, visto que a população que ocupava essas paragens reconhecia-se como parte integrante dessa totalidade. A partir disso pretendemos entender o papel da geografia nesse contexto e, para isso, é preciso recorrer um pouco à história dessa disciplina para compreender melhor a ciência geográfica, ou seja, verificar como o ensino de geografia era importante para a concretização do projeto de educação e sociedade almejado por Rui Barbosa no século XIX.

\section{A Questão do Ensino de Geografia para Rui Barbosa}

Para Rui Barbosa, o ensino de geografia constituía um elemento essencial da educação. "Acusar de aridez o estudo da geografia, o mesmo é que argüir de secura o oceano. Grande assombro seria o meu; se um menino bem dotado não fica-se-a amando acima de todas as outras ciências, desde que tha mostrassem sob a forma que the é própria" (HERDER apud BARBOSA, 1947b, p. 293).

Nenhum outro projeto educacional do século XIX contemplou com tanta prioridade o valor do ensino de geografia quanto o de Rui Barbosa. Os projetos educacionais que antecederam 0 dele somente citavam a geografia como componente do currículo escolar. Porém não aprofundaram suas análises a respeito da importância dessa disciplina. Apesar de sabermos que a geografia não era a única disciplina importante para Rui Barbosa, isso não inviabilizou que, em seus pareceres, tecesse considerações sobre a contribuição do ensino de geografia para a formação do cidadão brasileiro.

Ele comentava que, nos países civilizados, o ensino de geografia não era mais pautado em se repisar listas de nomes de países e cidades, e muito menos da indicação de sua posição geográfica. Foi com o emprego de um ensino diferente que esses países compunham cartas primorosas, nitidamente desenhadas, que abonavam as lições do mestre. Entretanto isso só foi possível por conta da aplicação dos processos intuitivos que possibilitavam uma profunda transformação pedagógica.

Rui Barbosa enfatizava que era importante permitir aos alunos que descobrissem sozinhos, o que os mestres lhes pretendiam ensinar, em vez de 0 aprenderem por transformações do livro. Argumentava que:

Na primary school americana servem-lhe de preparatório as lições de lugar. Depois de discernir as posições, adiante, atrás, à direita, à esquerda, acima, abaixo, o menino entra a discriminar a situação dos objetos na sala, a da sala na escola, a da escola na rua. Carecerá de grande esforço uma brasileira) é definido como sendo 0 da superação das formas rurais e arcaicas, que predominam na organização social colonial, pelas formas urbanas e modernas engendradas desenvolvimento capitalista" (CASTRO, 2008, p.133-134).

${ }^{6}$ Poderíamos aqui elencar uma série de historiadores que contribuíram sobre esta questão, porém, a título de esclarecimento, citaremos Euclides da Cunha que, em sua obra "Os Sertões", realizou um trabalho prodigioso, destacando a distância existente entre o sertanejo e a elite brasileira. Outro expoente que muito contribuiu com as questões geográficas brasileiras foi o Barão do Rio Branco, responsável em anexar importantes áreas para 0 Brasil.
Geografia Ensino \& Pesquisa, v. 15, n.3, p. 154 166, set./dez. 2011

Mormul, N. M.; Machado, M. C. G. Girotto, E. D.

\begin{tabular}{l|l} 
ISSN 2236-4994 & 159
\end{tabular} 
professora inteligente, para obter dos alunos que, antes de virem para a aula, averigúem a parte de onde 0 sol desponta, e tha vão dizer?(BARBOSA, 1947, p. 295).

Para ele, já era hora de romper com o marasmo e a inutilidade do ensino de geografia, bem como com o de outras ciências. Tornava-se imprescindível se apropriar dos conhecimentos científicos e reformar o país.

Rui Barbosa atribuía grande valor aos materiais didáticos e defendia o uso de mapas e globos para enriquecer as aulas e despertar o interesse das crianças. Salientava que todas as escolas deveriam possuir os materiais necessários para possibilitar aulas mais agradáveis.

Todavia Rui Barbosa explicava que, com o uso de globos e mapas-múndi, as crianças tomariam ciência do lugar que estavam e da distância entre as outras nações. "Empenha-se em tornar sensiveis aos olhos todas as suas explicações, em fazer, destarte, que as suas lições, sempre corretas, interessem às crianças, convertendo-se para elas num quase recreio" (BARBOSA, 1947, p. 298).

Para Rousseau, em sua obra "Emílio", o ensino de geografia, em vez de começar por intermédio dos globos e dos mapas, deveria começar pelos objetos mais próximos. Nessa obra, 0 autor enfatiza o uso da geografia regional.

Eu gostaria [...] de tomar a geografia por esses dois pontos e juntar ao estudo das revoluções do globo a medida de suas partes, começando pelo lugar em que habitamos. Enquanto a criança estuda a esfera e assim se transporta até os céus, trazei-a de volta à divisão da terra e mostrai-lhe primeiro sua própria morada. Seus dois primeiros pontos de geografia serão a cidade onde mora à casa de campo de seu pai; depois, os lugares intermediários, os rios dos arredores e finalmente 0 aspecto do sol e a maneira de se orientar. Esse é o ponto de encontro. Que ela faça por si mesma o mapa de tudo isso, mapa muito simples e formado inicialmente por dois únicos objetos, aos quais ela acrescenta pouco a pouco, à medida que vinha conhecendo ou avaliando suas distâncias e suas posições. [...] Que compreenda bem o que representam e tenha uma idéia nítida sobre a arte de traçá-los (ROUSSEAU, 1995, p. 210-211).

Quando nos referimos a Rousseau, não podemos deixar de comentar sobre a importância de Pestalozzi para o ensino de geografia, e Rui Barbosa sabia disso, porque ao propor o método intuitivo, já conhecia os preceitos desse grande educador. Pestalozzi defendia que 0 conhecimento era desenvolvido por meio das atividades cotidianas. Defendia a idéia de que era com a natureza que as crianças aprendiam geografia. Assim, o seu ensino não ficava preso a esquemas, mapas ou globos, só em contato com a terra, as primeiras noções de geografia seriam dadas.

Rui Barbosa defendia veementemente que, para ensinar geografia, era necessário manter contato direto com os recursos naturais e, desses recursos, saber proveitos tirar. Não poupou esforços em mostrar quão infinitamente longe estávamos dos moldes europeus e norteamericanos. Ao fazer isso, comparou os manuais elementares da geografia aos modelos

Geografia Ensino \& Pesquisa, v. 15, n.3, p. 154166, set./dez. 2011

0 Projeto Educacional de Rui Barbosa: $A$ questão do Ensino de Geografia e o Método Intuitivo europeus e norte-americanos e ridicularizava o uso da memória, afirmando que essa empobrecia o ensino de geografia, "[...] praticado assim pelo bordão da rotina, o ensino da geographia é inútil, embrutecedor. Nullo como meio de cultura, incapaz mesmo de atuar duradoiramente na memória, não faz senão oprimir, cançar e estupidificar a infância, em vez de esclarecê-la e educá-la" (BARBOSA, 1974, p. 307). 
Enfatizava a importância do uso de exemplos para a geografia e, ao tratar do ensino primário, colocou-a como substância principal, alertando sobre a ausência da figura humana nos compêndios geográficos e a necessidade de incorporar este assunto.

Ao considerar necessária uma educação para a vida, enfatizava que, nos Estados Unidos, no qual se compreendia profundamente essa questão, defendia-se que: "[...] a geografia elementar era uma homenagem necessária àqueles, dentre todos os interesses, que domina hoje os destinos das maiorias nações" (BARBOSA, 1947b, p. 315).

Percebia que a geografia poderia ser uma disciplina inspiradora, capaz de suscitar os desejos das crianças em conhecer e amar sua pátria. Do modo como era trabalhada nos países civilizados, poderíamos nós também utilizá-la para educar nossas crianças e alavancar 0 desenvolvimento econômico do nosso país.

O ensino da geografia vinha a constituir a moldura animada e pitoresca, dentro da qual se representava vivamente aos olhos do aluno o espetáculo da civilização contemporânea, com os seus recursos, lutas, dificuldades, conquistas, esplendores e contrastes de sombras. Assim, o aluno era conduzido suavemente até os limites, nos quais principiava o sistema da vida na superfície da terra, obra do meio que o envolvia com a pátria, com as águas e, finalmente, com 0 ambiente.

Para tanto, admitia-se que não existia outra ciência que causasse tanto agrado às crianças quanto a geografia, pois essa ciência tem o universo todo como palco de atuação. Basta, no entanto, para isso, conduzir as crianças para que se sintam parte desse universo. Para Spencer (1927, p. 3), "[...] o que importa não é aquilo que realmente somos, mas o que mostramos ser, assim, na educação, a questão não está no valor intrínseco dos nossos conhecimentos, mas nos seus efeitos extrínsecos sobre os outros".

Constitui-se ensino de geografia num poderoso instrumento para o desenvolvimento geral do pensamento, assim como familiarizar os alunos com o verdadeiro método de investigação científica, que contribui para despertar a curiosidade nos alunos, por meio de informações pertencentes a essa ciência.

Sendo assim, as crianças só se tornarão admiradoras da natureza, quando passarem a perceber as ligações existentes entre elas. 0 sentimento de amor e respeito pela natureza será despertado a partir da infância e, ao se sentirem integradas, irão conhecer e atribuir valores às coisas que estão ao seu redor. Com o passar dos anos, outros valores serão trabalhados, com o intuito de formar indivíduos conscientes e responsáveis pelo lugar que será ocupado por eles no futuro.

\section{O Método Intuitivo aplicado ao ensino de geografia}

Rui Barbosa enfatizou a urgência em reformular a instrução escolar, inclusive, a necessidade de adotar um novo método de ensino e defendia o uso dos sentidos para a aprendizagem. Era sincero ao dizer que um método estéril, como 0 usado até então, de nada serviria e definia o ensino atual como vão abstrato e morto. No parecer de Rui Barbosa sobre a reforma do ensino primário, o método intuitivo ${ }^{7}$ foi exaltado como o elemento mais importante de toda a reforma.

Cumpre renovar o método, orgânica, substancial, absolutamente, nas nossas escolas. Ou antes, cumpre criar o método; porquanto o que existe entre nós, usurpou um nome, que só por antífrase lhe assentaria: não é o
7 Veja o que escreve sobre 0 assunto Valdemarin (2004 p. 103). "Em meados do século XIX, o método intuitivo é entendido por seus propositores europeus e americanos como um instrumento pedagógico capaz de reverter a ineficiência do ensino escolar, que é assim pontuada: forma alunos com domínio insuficiente de leituras e escrita e com noções de cálculo insatisfatórias, principalmente pelo fato de alicerçar a aprendizagem exclusivamente na memória, priorizar a abstração, valorizar a repetição em detrimento da compreensão e impor conteúdos sem exame e discussão".

Geografia Ensino \& Pesquisa, v. 15, n.3, p. 154 166, set./dez. 2011

Mormul, N. M.; Machado, M. C. G. Girotto, E. D.

ISSN 2236- 4994

| 161 
${ }^{8}$ Num clima de descontentamento generalizado, expresso em enquetes, documentos oficiais e pareceres, 0 movimento de renovação pedagógica que começou a despontar na metade do século XIX, tenta investir contra o caráter abstrato e pouco utilitário da instrução, prescrevendo-lhe novo método de ensino, novos materiais, a criação de museus pedagógicos, variação de atividades, excursões pedagógicas, estudo do meio, entre outras. 0 raio de abrangência desse movimento pode ser avaliado também pelas sucessivas exposições universais, organizadas para a difusão de práticas pedagógicas renovadas, seus materiais e suas aplicações: Londres em 1862, Paris em 1867, Viena 1873, Filadélfia em 1876 , que deram origem ao Relatório de Buisson, países que se inserem no mesmo modo de produção e de circulação de mercadorias, embora com resultados e competências diversas. "[...] Os materiais didáticos difundidos neste período e nestas exposições compreendem, além do mobiliário escolar, caixas para ensino das cores e das formas, gravuras, coleções, objetos variados de madeira, aros, linhas, papéis etc. em substituição ao velho livro de textos para serem memorizados. Mas, a chave para desencadear a pretendida renovação é adoção de um novo método de ensino concreto, racional e ativo, denominado ensino pelo aspecto, lições de coisas ou ensino intuitivo" (VALDEMARIN, 2004, p. 104).

9 "[...] divulgado na Exposição de Filadélfia em 1876 e elogiado no Relatório por F. Buisson. Trata-se de um Manual para professores de ensino elementar aplicando metodologia intuitiva ao conteúdo

Geografia Ensino \& Pesquisa, v. 15, n.3, p. 154166, set./dez. 2011

\footnotetext{
O Projeto Educacional de Rui Barbosa: A questão do Ensino de Geografia e o Método Intuitivo

método de ensinar; é pelo contrario, o método de inabilitar para aprender. A criança, esse belo organismo, animado, inquieto, assimilativo, feliz, com os seus sentidos dilatados pela viveza das impressões como amplas janelas abertas para a natureza, com a sua insaciável curiosidade interior a atraí-la para a observação dos fenômenos que a rodeiam, com o seu instinto investigativo, com a sua irreprimível simpatia pela realidade com a sua espontaneidade poderosa, fecunda, criadora, com a sua capacidade incomparável de sentir a amar "o divino prazer de conhecer", a criança, nascida assim, sustentada assim pela independência dos primeiros anos, entra para o regime da escola, como flor, que retirassem do ambiente enérgico e luminosos do céu tropical, para experimentar na vida vegetativa da planta os efeitos da privação do sol, do ar livre, de todas as condições essenciais à natureza da pobre criaturinha condenada (BARBOSA, 1947, p. 33-34).

Diante disso, percebemos o quanto Rui Barbosa priorizava e necessidade de rever 0 método de ensino. Para tanto, estava sempre atento aos acontecimentos que versavam sobre educação escolar em todo o mundo. Entre esses acontecimentos, destacam-se as Exposições Internacionais, que ocorreram em alguns países da Europa e das Américas entre os anos de 1851 e 1922, que constituiriam importantes ambientes de discussões e revelações referentes à educação no século XIX. Tinham como objetivo expor os produtos aos visitantes e eram vistas como verdadeiras festas didáticas.

Neste caso, os ambientes de discussões contribuiriam para a divulgação de novos métodos de ensino e materiais pedagógicos ${ }^{8}$. Vale destacar que participavam dessas exposições pessoas das mais diferentes formações, como: políticos, médicos, militares, professores, religiosos, engenheiros, o que possibilitou a circulação dos novos saberes pedagógicos, que eram considerados de derradeira importância para o desenvolvimento das nações.

Em meio a esses novos saberes pedagógicos, destaca-se o método intuitivo e as "Lições de Coisas", do qual Rui Barbosa se apropriou ao redigir seus pareceres. Estes encontraram, nessas exposições, um espaço bastante proveitoso para sua divulgação, bem como sua explicação. 0 manual "Lições de Coisas" foi mencionado a Rui Barbosa em 1879 na Exposição Pedagógica Internacional na Filadélfia. ${ }^{9}$

Desde então e por mais de meio século, lutou-se nos Estados Unidos pela implantação das práticas do ensino intuitivo ante as dificuldades que sentiam os docentes em se adaptarem, por conta própria a estas práticas. As idéias de Pestalozzi quanto à prática corrente do ensino compunha um formulário de lições, que foi publicado em 1861. Buisson se referiu à obra de Calkins como a melhor coleção de Lições de Coisas. Rui Barbosa, então, conheceu-a em fins de 1880 na $18^{a}$ edição (SCHELBAUER, 2003).

Segundo Rui Barbosa, o método intuitivo ou Lições de Coisas, deveria ser usado especialmente no ensino primário.

Como um saber pedagógico em circulação na Europa e Estados Unidos, a partir da segunda metade do século XIX, o método intuitivo desembarca na realidade brasileira, trazendo os elementos da renovação educacional que, de acordo com os nossos intelectuais ilustrados, poderiam modificar o cenário da nação, modernizando-a através da educação. Apesar de não se constituir em um saber inteiramente desconhecido entre nós, foi somente a partir da década de 1870 que ela começou a se destacar na educação brasileria, tanto no pano dos discursos, como no das iniciativas, ganhando ênfase no decorrer da década de 1880 e, sobretudo, durante a década de 1890, quando se consubstancia com as reformas republicanas da instrução pública (SCHELBAUER, 2003, p. 81). 
Esse método pautava-se numa compreensão filosófica e científica, por meio da qual a obtenção de conhecimento seria oriunda dos sentidos e da observação. Fundamentado nas idéias de Pestalozzi e Froebel, implicava uma abordagem indutiva, na qual o ensino deveria partir do particular para o geral, do conhecido para o desconhecido, do concreto para o abstrato. Por isso, seria necessário romper com o método vigente e passar a trabalhar com o método intuitivo, que se desdobrava em "Lições de Coisas". Rui Barbosa, inclusive, elogiou a introdução das "Lições de Coisas" no Brasil, por meio do Decreto de Leôncio de Carvalho, do qual ele foi o responsável em emitir os pareceres, mas evidenciou que havia divergência de entendimento entre ele e seu companheiro de causa sobre essa questão. Essa diferença foi explicitada como segue:

Desacertou, porém, indigitando-as como capítulo singular, distinto, independente entre as matérias do programa. Nada contribuiria mais para inutilizar de todo essa inovação, para levar a uma degenerescência imediata, do que uma especialização tal, que parte da compreensão imperfeita da natureza deste ensino. A lição de coisas não é assunto especial no plano de estudos: é um método de estudos; não se circunscreve a uma secção do programa: abrange o programa inteiro; não se ocupa, na classe, um lugar separado, como a leitura, a geografia; 0 cálculo, ou as ciências naturais: é o processo geral, a que se devem subordinar todas as disciplinas professadas na instrução elementar. No pensamento do substitutivo, pois, a lição de coisas não se inscreve no programa; porque constitui o espírito dele; não tem lugar exclusivo no horário; preceitua-se para o ensino de todas as matérias, como o método comum, adaptável e necessário a todas (BARBOSA, 1947, p. 214-215).

Leôncio de Carvalho foi o precursor das Lições de Coisas no Brasil, mas, como salientamos Rui Barbosa não concordou com o modo que ele a apresentou em seu projeto. $\mathrm{E}$ Schelbauer (2003, p. 83) comenta sobre essa questão:

As lições de coisas, forma pela qual também foi vulgarizado o método intuitivo, forma preconizada, pela primeira vez na legislação brasileira através da reforma liberal Leôncio de Carvalho, em 1879. No entanto, é importante salientar que o método já havia sido anunciado em algumas iniciativas educacionais, trazendo à tona os intelectuais vinculados a elas e evidenciando o seu papel de destaque no movimento de renovação pedagógica que se instaura no país a partir da década de 1870. A historiografia educacional tem oferecido significativas contribuições acerca dessas iniciativas e desses intelectuais, tanto no âmbito da instrução pública como no da particular, durante a década de 1870.

Rui Barbosa era muito convicto ao enfatizar que, além da reforma dos métodos, era necessária a reforma dos mestres. A reforma do método não deveria ser, para ambos, simples alteração da mecânica escolar, mas a reforma dos costumes e da mentalidade de nossa gente e destacava que a instrução inspirada em "Lições de Coisas" não seria uma instrução acerca das coisas, mas a instrução pelas próprias coisas. Neste sentido, propôs cursos para formação de professores com duração de quatro anos, freqüência obrigatória e, nos quais seria exigido 0 conhecimento de língua estrangeira.

0 curso de formação de professores era o ponto chave da reforma porque a introdução de inovações na escola dependia, primordialmente, da ação do professor que, neste caso, deveria ser formado com esta finalidade. 0 método seria inseparável do mestre, ou seja, o mestre é 0 método animado. Por isso, quando se tratava de introduzir novos sistemas pedagógicos, o primeiro passo era formar professores capazes de executá-los. do ensino. Consiste em atividades pedagógicas por meio das quais é possivel educar os sentidos e depois aplicar esta acuidade à aprendizagem do programa escolar" (VALDEMARIN, 2000, p. 153).
Geografia Ensino \& Pesquisa, v. 15, n.3, p. 154 166, set./dez. 2011

Mormul, N. M.; Machado, M. C. G. Girotto, E. D. 
Assim, propunha uma formação permeada por um caráter técnico: ensinar a ensinar, educar no método de educar, esta era a finalidade da escola normal. A formação profissional abrangeria todas as disciplinas, uma vez que não se tratava apenas de adquirir conhecimento específico em determinada área, mas de aprender a ensinar metódica e eficazmente. Por isso, os exercícios práticos iniciar-se-iam nos primeiros anos nas escolas primárias anexas e nos jardins de infância.

Portanto, Rui Barbosa concordava que o professor deveria receber a preparação adequada a fim de repassar aos seus futuros alunos as influências intelectuais e morais indicadas no plano de estudos da primeira idade. Desta maneira, a formação de professores seria tanto técnica quanto prática. Pestalozzi defendia a observação como base de todo o conhecimento, porém devia-se habituar 0 menino a observar exatamente, e depois a exprimir corretamente o resultado do que observara.

Com o emprego do método intuitivo, havia a preocupação iminente em fazer com que a criança se reconhecesse como parte do meio. Os sentidos eram amplamente explorados, para que, por meio deles, as crianças se apropriassem dos conhecimentos, ou seja, os elementos fundamentais da educação primária eram os eixos, que norteavam as "Lições de Coisas": observação e comparação. A obra "Lições de Coisas" possibilitou e, de certa forma, potencializou a tradução do conhecimento científico em noções elementares para 0 uso nas escolas. Nesse aspecto, fez do método intuitivo um meio eficaz e audacioso para que a educação realmente se expandisse para além dos muros escolares.

Diante disso, era preciso estimular a curiosidade em detrimento do excesso de memorização. Precisava-se estimular a criança a entender o que ela aprendia, portanto, era necessária a adoção de um método novo que proporcionasse 0 desenvolvimento geral do indivíduo. Entretanto era imprescindível que fosse precedida por uma reforma no programa da escola primária do país.

\section{Considerações Finais}

O breve panorama realizado neste trabalho a respeito da situação do ensino no Brasil, em especial o ensino de geografia, com ênfase no programa proposto por Rui Barbosa, no qual se discutiu a questão da identidade nacional, bem como a participação do ensino de geografia para a realização do projeto de Rui Barbosa. Possibilitou-nos verificar que o ensino de geografia poderia ter sido um forte aliado para a concretização dos projetos de desenvolvimento da nação, mas, infelizmente, as mudanças não saíram do papel e muito do que propôs Rui Barbosa só começou a se efetivar na República, com trabalhos de outros intelectuais.

Rui Barbosa estava certo ao afirmar que o Brasil estava longe dos moldes europeus. Acreditava, que seu projeto de ensino atendia as necessidades das pessoas e a reforma por ele proposta prepararia a criança para a vida. No entanto, era necessário um ensino diferente do existente, e para isso, novos conteúdos seriam privilegiados e os existentes seriam trabalhados de modo diferente, fazendo uso do método intuitivo. Assim, o aprendizado estaria sendo guiado

Geografia Ensino \& Pesquisa, v. 15, n.3, p. 154166, set./dez. 2011

O Projeto Educacional de Rui Barbosa: A questão do Ensino de Geografia e o Método Intuitivo ISSN 2236- 4994 pelo uso dos sentidos e com base nele seria trabalhada a geografia. Embora fosse reconhecida a sua importância do ensino de geografia, de acordo com Rui Barbosa estava sendo pormenarizada no currículo escolar em virtude da maneira como era ensinada.

Dessa forma, podemos entender o projeto de Rui Barbosa como um preparativo para as mudanças que se processavam na transição do Brasil imperial para o republicano. Não obstante, o ensino de geografia entre tantos conteúdos, estava munido de informações 
importantes, capaz de suscitar o espirito nacional e contribuir, de modo bastante eficaz, para disseminar o ideário patriótico e ainda efetivar sua identidade.

\section{Referências}

BARBOSA, R. Reforma do ensino primário e várias instituições complementares da instrução pública. Obras Completas. Rio de Janeiro: Ministério da Educação e Saúde, v. X, t, II, 1947

CASTRO, M. H. M. O sentido da Revolução Brasileira em Raízes do Brasil. Disponível em <http://www.esg.br/cee/ARTIGOS/mhenrique2.pdf>. Acesso em: 20 mar. 2008.

LESSER, J. A negociação da identidade nacional: imigrantes, minorias e a luta pela etnicidade no Brasil. São Paulo: Editora UNESP, 2001.

MACHADO, M.C.G. Fontes e história das instituições escolares: 0 projeto educacional de Rui Barbosa no Brasil. In: LOMBARDI, J. C; NASCIMENTO, M. I. M (Org.). Fontes, história e historiografia da educação. v.1. Campinas, SP: Autores Associados, 2004. p. 65-83.

MONTEIRO, J, M. Raízes da América Latina. São Paulo: Edusp, 2001.

ROUSSEAU, J. J. Emílio. Trad. Roberto Leão Ferreira. São Paulo: Martins Fontes, 1995.

SCHELBAUER, A. A constituição do método de ensino intuitivo na Província de São Paulo (1870 - 1889). São Paulo, Faculdade de Educação da Universidade de São Paulo, 2003. (Tese de Doutorado).

SPENCER, H. Educação intellectual, moral e physica. Porto: Livraria Chardron, 1927.

VALDEMARIN, Vera Teresa. O liberalismo demiurgo: Estudo sobre a reforma educacional projetada nos pareceres de Rui Barbosa. São Paulo: Cultura Acadêmica, 2000.

Estudando as Lições de Coisas: análise dos fundamentos filosóficos do Método Intuitivo. Campinas, SP: Autores Associados, 2004. 